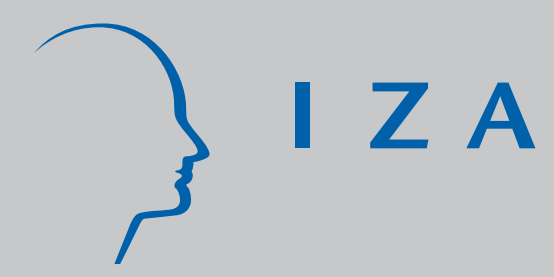

IZA DP No. 2071

A Selection-Based Theory of the Transition from Employment to Entrepreneurship:

The Role of Employer Size

Simon C. Parker

April 2006 


\title{
A Selection-Based Theory of the Transition from Employment to Entrepreneurship: The Role of Employer Size
}

\author{
Simon C. Parker \\ Durham University \\ and IZA Bonn
}

Discussion Paper No. 2071

April 2006

IZA
P.O. Box 7240
53072 Bonn
Germany

Phone: +49-228-3894-0

Fax: +49-228-3894-180

Email: iza@iza.org

\begin{abstract}
Any opinions expressed here are those of the author(s) and not those of the institute. Research disseminated by IZA may include views on policy, but the institute itself takes no institutional policy positions.

The Institute for the Study of Labor (IZA) in Bonn is a local and virtual international research center and a place of communication between science, politics and business. IZA is an independent nonprofit company supported by Deutsche Post World Net. The center is associated with the University of Bonn and offers a stimulating research environment through its research networks, research support, and visitors and doctoral programs. IZA engages in (i) original and internationally competitive research in all fields of labor economics, (ii) development of policy concepts, and (iii) dissemination of research results and concepts to the interested public.
\end{abstract}

IZA Discussion Papers often represent preliminary work and are circulated to encourage discussion. Citation of such a paper should account for its provisional character. A revised version may be available directly from the author. 
IZA Discussion Paper No. 2071

April 2006

\section{ABSTRACT \\ A Selection-Based Theory of the Transition from Employment to Entrepreneurship: The Role of Employer Size}

A simple occupational choice model is used to predict that entrepreneurs who found new firms are more likely to work for small than for large firms prior to start-up. The mechanism underlying the result is heterogeneous risk aversion. The model also predicts a positive association between new firm formation and previous self-employment experience. These predictions accord with previous empirical findings, but notably self-selection rather than productivity effects can explain them.

JEL Classification: J21, J23, J62

Keywords: entrepreneurship, occupational choice, firm size

Corresponding author:

Simon C. Parker

School of Economics, Finance \& Business

23-26 Old Elvet

Durham DH1 3HY

United Kingdom

Email: S.C.Parker@durham.ac.uk

* I am grateful to Sanjay Banerji and C. Mirjam van Praag for helpful comments on earlier drafts. 


\section{Introduction}

Individuals do not randomly become entrepreneurs. Many individual-specific factors are known to affect this occupational choice (Parker, 2004). But there is growing awareness that firm-specific factors also affect the decision to become an entrepreneur. For example, Gompers et al (2005) provide evidence that location, age, and diversification strategies of incumbent firms are associated with the tendency for their employees to quit and become entrepreneurs. This paper provides a theoretical analysis of the relationship between new venture creation and a particularly salient characteristic of incumbent firms: their size.

In the broader economic and social context, a better understanding of individuals' choices to become entrepreneurs is of central importance to the policy community, as well as to academic researchers. The European Commission Green Paper on Entrepreneurship (2003) is only one of a recent raft of policy initiatives aimed at promoting entrepreneurship in Europe. As noted in that paper, "the challenge for the European Union is to identify the key factors for building a climate in which entrepreneurial initiative and business activities can thrive. Policy measures should seek to boost the Union's levels of entrepreneurship, adopting the most appropriate approach for producing more entrepreneurs and for getting more firms to grow" (European Commission, 2003, p. 9). Hence it is practically useful as well as academically valuable to explore why individuals choose to start up new firms. This article explores a central question - the reasons why small firms produce a disproportionate number of entrepreneurs.

The available evidence suggests that individuals with particular kinds of work experience are more likely to become entrepreneurs. Three findings from the empirical entrepreneurship literature are especially pertinent to our study. One is that previous self-employment experience is positively associated with a tendency to enter self-employment subsequently, whereas previous employment experience has little or no such effect (Evans and Leighton, 1989; van Praag and van Ophem, 1995). A second relevant finding is that employees of small firms are more likely to switch into self-employment than their counterparts in large firms are (Boden, 1996; Wagner, 2004). Third, younger firms (which tend to be smaller) spawn more entrepreneurs on average than older ones do (Gompers et al, 2005). However, our theoretical 
understanding of the reasons for these outcomes remains somewhat opaque.

We attempt to shed light on these issues by setting up in Section 2 a simple occupational choice model with owners and workers who differ from each other in terms of their risk attitudes, and in which the identity of new firm owners ('entrepreneurs') is endogenous. Section 3 uses the model to derive a sequence of results regarding the nature of the available employment contracts, the sorting of workers between large and small firms, and the identities of the workers who become entrepreneurs. This constitutes a selection-based story which contrasts with an alternative explanation in which workers in small firms can more easily gain productive experience or observe or learn from 'role model' entrepreneurs, thereby becoming better placed to enter entrepreneurship later on. The final section concludes by identifying linkages between our model and other related work in the literature.

\section{The Model: Assumptions and Notation}

The economy comprises three types of firm: 'large', 'small', and 'outside'. These three types are discrete and have the following characteristics. Large firms are protected by entry barriers, so neither small firm owners nor their employees can change status to add to the number of large firms. Regarding occupational choice between being a small firm owner and a worker, choice is limited by the existence of product niches. Niches can be thought of as brand names that confer some market power. Each small firm owner profitably exploits one and only one niche. The total number of niches is initially fixed, preventing entry into small firms as well; later on we study occupational choice when the number of niches increases exogenously. ${ }^{1}$ Large firms are taken to maximise expected returns, either because they are risk neutral or because they are fully diversified. In contrast, small firm owners and workers are risk averse and maximise expected utility, having utility functions $U(x ; r)$, where $x$ is the (possibly state-dependent) payoff and $r$ indexes risk aversion (see below). Niches enable small and large firms to co-exist in product markets. The third type of firm, called 'outside firms',

\footnotetext{
${ }^{1}$ As we will discuss below, niches could alternatively be replaced with a market imperfection such as borrowing constraints; our results would still go through, but niches simplify the exposition and abstract from what are in the context of this paper secondary issues related to credit markets.
} 
offers a fixed wage $w>0$ to workers. They do not compete directly in the product market with either small or large firms. One might perhaps choose to think of outside firms as multinationals whose operations are spread over many countries, unlike domestic small and large firms. In any event, the next section will clarify the purpose of including outside firms in the model.

All workers work individually, i.e., not in teams. Production takes place in a single period. Workers produce a high level of output $\bar{S}$ with a common exogenous probability $\pi \in[0,1]$ and a low level of output $\underline{S}$ with probability $1-\pi$, where $\bar{S}>\underline{S}>0$. Owners receive the output and remunerate workers with transfers, derived below, that are denoted by $t^{*}$ if they are state-independent, and by $\left(\bar{t}^{*}, \underline{t}^{*}\right)$ if they are state-dependent. There are no restrictions on the number of workers that owners can hire: more workers just scale up their total output. Hence there is always an owner available for a worker to match with if they wish to. All actors have complete information apart from future realisations of $\tilde{S} \in\{\bar{S}, \underline{S}\}$. We will initially assume that workers supply contractible effort; in the next section, we go on to consider the possibility of imperfect information about discretionary worker effort.

There are two types of worker in the economy, who differ only in terms of their risk aversion; in all other respects they are identical. With a fixed number of niches, each worker chooses which type of firm to work for. If the opportunity arises (i.e., the number of niches exogenously increases), workers can also choose whether to become an entrepreneur running their own small firm; this case will be treated later. The type of a worker is indexed by $r$, where $r \in\{\alpha, \beta\}$. This set of types includes workers with relatively low levels of risk aversion, $r=\alpha>0$, and workers with higher levels of risk aversion, $r=\beta>\alpha$. It will be convenient below to write the transfers received by workers of a given type by $t_{r}^{*}\left[\right.$ or $\left.\left(\bar{t}_{r}^{*}, \underline{t}_{r}^{*}\right)\right]$. The owners of small firms have risk aversion $\gamma>0$. Denote by $\psi_{r}$ a worker $r$ 's expected utility from the next best alternative occupation to being a worker in their chosen firm. The values of the $\left\{\psi_{r}\right\}$ in competitive equilibrium will be derived below.

Two final assumptions rank the payoffs from being owners or workers under the various state of nature. First we stipulate

$$
\text { A1 : } \quad \bar{S}-\bar{t}_{r}^{*}>\underline{S}-\underline{t}_{r}^{*} \geq \bar{t}_{r}^{*} \geq \underline{t}_{r}^{*} \quad \text { for each } r .
$$


Thus net profits from being a firm owner in the good state exceed those in the bad state. The fact that the firm owner's profits are also higher in the bad state than are the worker's wages in the good state is indicative of the value of niches. In fact, this assumption is stronger than we need, which is merely that all individuals receive unambiguously higher expected payoffs as an owner than as a worker. That ensures there will be market entry (i.e., entrepreneurship) when the number niches expands. Second, we will assume that

$$
\mathrm{A} 2: \quad \gamma=\min \{\alpha, \beta\}=\alpha,
$$

i.e., small firm owners are as risk averse as the least risk-averse worker. Given A1, assumption A2 ensures that the expected utility of being an owner is also unambiguously higher than that of a worker. This also highlights the importance of a fixed number of niches. Workers of both types might prefer to be a small firm owner, but are restricted from doing so by the fixed number of niches.

\section{Results}

The first two parts of this section focus on the nature of employment contracts and the allocation of workers to firms when the number of product niches is fixed. The third part extends the model to consider the effects of incorporating moral hazard, while the final part determines which firms generate the entrepreneurs when the number of niches increases.

\subsection{Offered contracts}

The small firm owner designs a contract for agents with risk aversion $r$ that solves the following problem:

$$
\begin{aligned}
\max _{\left\{\left(\bar{t}_{r}, \underline{t}_{r}\right)\right\}} & \pi U\left(\bar{S}-\bar{t}_{r} ; \gamma\right)+(1-\pi) U\left(\underline{S}-\underline{t}_{r} ; \gamma\right) \\
\text { s.t. } & \pi U\left(\bar{t}_{r} ; r\right)+(1-\pi) U\left(\underline{t}_{r} ; r\right) \geq \psi_{r}
\end{aligned}
$$

where (3) is the expected utility of the owner and (4) is worker $r$ 's participation constraint, where $\psi_{r}$ is the expected utility $r$ derives from her next best alternative to working for the small firm. The values of $\left\{\psi_{r}\right\}$ under competitive equilibrium are not exogenous in this problem and will be derived 
below.

Let $\lambda$ denote the Lagrange multiplier for this concave programming problem. The first order conditions are:

$$
\begin{aligned}
-\pi U^{\prime}\left(\bar{S}-\bar{t}_{r}^{*} ; \gamma\right)+\lambda \pi U^{\prime}\left(\bar{t}_{r}^{*} ; r\right) & =0 \\
-(1-\pi) U^{\prime}\left(\underline{S}-\underline{t}_{r}^{*} ; \gamma\right)+\lambda(1-\pi) U^{\prime}\left(\underline{t}_{r}^{*} ; r\right) & =0
\end{aligned}
$$

From (5) and (6) it follows that

$$
\begin{aligned}
\lambda=\frac{U^{\prime}\left(\bar{S}-\bar{t}_{r}^{*} ; \gamma\right)}{U^{\prime}\left(\bar{t}_{r}^{*} ; r\right)} & =\frac{U^{\prime}\left(\underline{S}-\underline{t}_{r}^{*} ; \gamma\right)}{U^{\prime}\left(\underline{t}_{r}^{*} ; r\right)}>0 \\
\frac{U^{\prime}\left(\bar{t}_{r}^{*} ; r\right)}{U^{\prime}\left(\underline{t}_{r}^{*} ; r\right)} & =\frac{U^{\prime}\left(\bar{S}-\bar{t}_{r}^{*} ; \gamma\right)}{U^{\prime}\left(\underline{S}-\underline{t}_{r}^{*} ; \gamma\right)}
\end{aligned}
$$

It follows from (7) that the constraint (4) binds and can be imposed as an equality below. However, the trial solution $\bar{t}_{r}^{*}=\underline{t}_{r}^{*}$ does not allow (7) to hold with equality, so we must have $\bar{t}_{r}^{*}>\underline{t}_{r}^{*}$. Hence there is incomplete insurance across states for both small firm owners and workers. In contrast, the riskneutral large firm owner optimally sets $\bar{t}_{r}^{*}=\underline{t}_{r}^{*}=t_{r}^{*}$, i.e., they completely insure their workforce.

\subsection{Allocation of workers to firms}

Next we study the participation constraints in greater detail and derive an equilibrium allocation of workers to firms. Recall that there are two types of worker $(\alpha$ and $\beta$ ) and three types of firm (small - with risk averse owners; large - with risk neutral owners; and outside - offering a fixed wage $w$ ). Each worker can freely choose between working for any of these firms for a known firm-specific compensation contract. We begin by showing that the contracts sought by $\beta$ types in small firms are always dominated (outbid) by the contracts that $\alpha$ types would take; while the contracts sought by $\alpha$ types are always dominated (outbid) in large firms by the contracts that $\beta$ types would take. Hence $\alpha$ types end up joining small firms and $\beta$ types end up joining large (or outside) firms. Outside firms turn out to be necessary to support a non-trivial competitive separating equilibrium with a unique allocation of workers to firms.

Suppose to start with that $\alpha$ types are indeed employed by small firms, and $\beta$ are employed by large firms, so we can define two compensation 
contracts $\Gamma_{\alpha}:=\left(\bar{t}_{\alpha}^{*}, \underline{t}_{\alpha}^{*}\right)$ and $\Gamma_{\beta}:=t_{\beta}^{*}$. Consider a deviation from this rule, whereby $\beta$ types covet the contract $\Gamma_{\alpha}$. This contract would have to satisfy

$$
E U\left(\Gamma_{\alpha} ; \beta\right) \geq U\left(\Gamma_{\beta} ; \beta\right)
$$

where $E$ is the expectations operator. As $\beta>\alpha$, it follows using (8) that

$$
\frac{U^{\prime}\left(\bar{t}_{\alpha}^{*} ; \beta\right)}{U^{\prime}\left(\underline{t}_{\alpha}^{*} ; \beta\right)}<\frac{U^{\prime}\left(\bar{t}_{\alpha}^{*} ; \alpha\right)}{U^{\prime}\left(\underline{t}_{\alpha}^{*} ; \alpha\right)}=\frac{U^{\prime}\left(\bar{S}-\bar{t}_{\alpha}^{*} ; \gamma\right)}{U^{\prime}\left(\underline{S}-\underline{t}_{\alpha}^{*} ; \gamma\right)}
$$

Hence $\Gamma_{\alpha}$ is not optimal for $\beta$ types because it offers them too little insurance: (9) does not hold. But an alternative contract $\Gamma_{\beta}^{\Delta}:=\left(\bar{t}_{\beta}^{*}, \underline{t}_{\beta}^{*}\right)$ such that $E U\left(\Gamma_{\beta}^{\Delta} ; \beta\right) \geq U\left(\Gamma_{\beta} ; \beta\right)$ must have $\bar{t}_{\beta}^{*}<\bar{t}_{\alpha}^{*}$ and $\underline{t}_{\beta}^{*}>\underline{t}_{\alpha}^{*}$, because of the greater concavity of the utility function of $\beta$ types. However, risk-averse small firm owners will not accept this because $E U\left(\tilde{S}-\Gamma_{\beta}^{\Delta} ; \gamma\right)<E U\left(\tilde{S}-\Gamma_{\alpha} ; \gamma\right)$ : i.e., the alternative contract that suits $\beta$ types leaves the small firm owners bearing too much risk. Hence the contracts sought by $\beta$ types in small firms are always dominated by the contracts that $\alpha$ types would take.

Would $\alpha$ types want to deviate from the contract $\Gamma_{\alpha}$ ? Large firm owners have the incentive to reduce $\Gamma_{\beta}$ until the participation constraint (4) holds with equality for $\beta$ s: i.e., until $U\left(\Gamma_{\beta} ; \beta\right)=\psi_{\beta}=E U\left(\Gamma_{\alpha} ; \beta\right)$. Because $\alpha<\beta$ $\Rightarrow E U\left(\Gamma_{\alpha} ; \alpha\right)>E U\left(\Gamma_{\alpha} ; \beta\right)$, it follows that ${ }^{2}$

$$
E U\left(\Gamma_{\alpha} ; \alpha\right)>U\left(\Gamma_{\beta} ; \alpha\right)
$$

i.e., $\alpha$ types will not covet the other contract, $\Gamma_{\beta}$. Finally, consider a contract $t_{\alpha}^{*}$ that $\alpha$ types would find acceptable in large firms. This would have to satisfy

$$
E U\left(\Gamma_{\alpha} ; \alpha\right) \leq U\left(t_{\alpha}^{*} ; \alpha\right)
$$

But by comparing (11) and (12), this requires $t_{\alpha}^{*}>t_{\beta}^{*}$. Hence the contracts sought by $\alpha$ types in large firms are always dominated (outbid) by the contracts that $\beta$ types would take.

This establishes that $\alpha$ types match with small firms and receive $\Gamma_{\alpha}$, while $\beta$ types match with large firms and receive $\Gamma_{\beta}$. By itself, however, this does not constitute a competitive equilibrium. To see why, notice that

\footnotetext{
${ }^{2}$ Strictly speaking, the inequality in (11) requires only marginal differences in risk aversion between the types such that $U(x ; \alpha) \approx U(x ; \beta)$ for any certain payoff $x$.
} 
the strict preferences of $\alpha$ types for $\Gamma_{\alpha}$ over $\Gamma_{\beta}$, and of $\beta$ types for $\Gamma_{\beta}$ over $\Gamma_{\alpha}$, always allows owners to reduce returns until the participation constraint (4) holds for both types. So, for example, the small firm owner can always bid down the average value of $\Gamma_{\alpha}$ until the $\alpha$ workers are indifferent between the reduced $\Gamma_{\alpha}$ in the small firm and $\psi_{\alpha}=U\left(\Gamma_{\beta} ; \alpha\right)$ in a large firm. Recall however that $\psi_{\beta}=E U\left(\Gamma_{\alpha} ; \beta\right)$ is the $\beta$ workers' expected utility in the alternative occupation. So as the small firm owners bid down $\Gamma_{\alpha}$, the large firm owner rationally also bids down $\Gamma_{\beta}$ to force equality in $\beta$ workers' participation constraints. This in turn enables the small firm owners to bid down their transfers $\Gamma_{\alpha}$ further, and so the process continues in an endless race to the bottom.

The outside offer of $w>0$ effectively provides a floor to returns and halts the downward bidding process (this is the purpose of the outside firms). The outside wage leaves all of the previous analysis unchanged, including the result that $\alpha$ type workers match with the small firms while the $\beta$ type workers match with large firms. But now $\beta$ types have

$$
U\left(\Gamma_{\beta} ; \beta\right)=U(w ; \beta)>E U\left(\Gamma_{\alpha} ; \beta\right)
$$

So in equilibrium, large firm owners can force $t_{\beta}^{*}$ down as far as, but no further than, $w$, so $\psi_{\beta}=U(w ; \beta)$. Thus $\beta$ s receive $\Gamma_{\beta}=t_{\beta}^{*}=w$ from large firm owners, and are indifferent between working for a large or an outside firm. Likewise for $\alpha$ types the equality $E U\left(\Gamma_{\alpha} ; \alpha\right)=\psi_{\alpha}=U(w ; \alpha)$ together with (5) and (6) determine $\left(\Gamma_{\alpha}, \lambda\right)$, where $\bar{t}_{\alpha}^{*}>t_{\beta}^{*}>\underline{t}_{\alpha}^{*}$. This constitutes a competitive separating equilibrium because none of the owners or workers have any incentive to deviate from it.

\subsection{Extending the model to incorporate moral hazard}

The analysis so far abstracts from workers' costs of supplying effort. We can now ask how the results would change if moral hazard (non-contractible effort) is introduced into the model. This transforms the problem into a principal-agent (rather than owner-worker) problem. The programming problem is now characterised by choosing $\left(\bar{t}_{r}, \underline{t}_{r}\right)$ to maximise (3) (for $\gamma \geq 0$ ) 
subject to

$$
\begin{aligned}
\pi U\left(\bar{t}_{r} ; r\right)+(1-\pi) U\left(\underline{t}_{r} ; r\right)-c & \geq \pi_{0} U\left(\bar{t}_{r} ; r\right)+\left(1-\pi_{0}\right) U\left(\underline{t}_{r} ; r\right) \\
\pi U\left(\bar{t}_{r} ; r\right)+(1-\pi) U\left(\underline{t}_{r} ; r\right) & \geq \psi_{r}
\end{aligned}
$$

where $c>0$ is the cost of supplying high effort, and $\pi_{0}<\pi$ (resp., $\pi$ ) is the probability of a good outcome when low (resp., high) effort is supplied. When (13) and (14) both bind, the solution is independent of the principal's risk aversion, and for workers in both small and large firms is given by

$$
\begin{aligned}
& \bar{t}_{r}^{*}=h_{r}\left(\psi_{r}+\frac{(1-\pi) c}{\pi-\pi_{0}}\right) \\
& \underline{t}_{r}^{*}=h_{r}\left(\psi_{r}-\frac{\pi c}{\pi-\pi_{0}}\right),
\end{aligned}
$$

where $h_{r}=U^{-1}(\cdot ; r)$ is the inverse function of $U(\cdot ; r) .{ }^{3}$ The $h$ function is increasing and convex in its income argument $\left(h^{\prime}, h^{\prime \prime}>0\right)$, so the difference between $\bar{t}_{r}^{*}$ and $\underline{t}_{r}^{*}$ is greater the less risk averse the agent. This is logical: less risk-averse agents have to be incentivised to supply privately costly effort by a greater spread of transfers in the different states.

This implies that less risk averse $\alpha$ agents will tolerate more variable returns than $\beta$ agents. Hence $\alpha$ agents generate less variable returns for principals than $\beta$ agents. This is valuable for small firm principals (who are risk averse) but not for large firm principals, who are risk neutral. Hence once again, even in the presence of moral hazard, less risk-averse workers match with small firm principals. Thus our matching results from earlier are robust to this extension of the model.

\subsection{Which firms do entrepreneurs come from?}

Having determined the allocation of workers to owners, we can now ask who will become an entrepreneur and set up a new small firm if the number of niches exogenously increases. It will be assumed that when a new niche becomes available, all workers have the opportunity to set up a firm in an attempt to establish the dominant firm in the niche. To abstract from

\footnotetext{
${ }^{3}$ These solutions are obtained by replacing the weak inequalities in (13) and (14) with strict equalities and solving for $\left[U\left(\bar{t}_{r}^{*} ; r\right), U\left(\underline{t}_{r}^{*} ; r\right)\right]$ — from which (15) and (16) follow directly. See Laffont and Martimort (2002) for a detailed exposition.
} 
unnecessary complexity, the occupancy of the niche in a dominant firm is taken to be assigned randomly from among the entrepreneurs with the lowest costs. ${ }^{4}$ To determine the characteristics of the lowest cost entrepreneurs, we will first analyse outcomes when the entrant has some general unspecified degree of risk aversion, $\delta$. We then consider the outcomes when $\delta$ takes the specific values associated with the two worker types, and conclude by establishing which of the incumbent firms employs the workers who optimally become the entrepreneurs.

First consider the case where $\delta>\gamma$. If an individual with relatively high risk aversion $\delta$ becomes an entrepreneur we would have

$$
\frac{U^{\prime}\left(\bar{t}_{\alpha}^{*} ; \alpha\right)}{U^{\prime}\left(\underline{t}_{\alpha}^{*} ; \alpha\right)}=\frac{U^{\prime}\left(\bar{S}-\bar{t}_{\alpha}^{*} ; \gamma\right)}{U^{\prime}\left(\underline{S}-\underline{t}_{\alpha}^{*} ; \gamma\right)}>\frac{U^{\prime}\left(\bar{S}-\bar{t}_{\alpha}^{*} ; \delta\right)}{U^{\prime}\left(\underline{S}-\underline{t}_{\alpha}^{*} ; \delta\right)} .
$$

Analogous to (10), to equate the first and third terms of (17) it is necessary to change the transfers from $\Gamma_{\alpha}$ to something else. Denote the transfers offered to $\alpha$ workers by owners with risk aversion $\delta$ by $\Gamma_{\alpha \delta}=\left(\bar{t}_{\alpha \delta}^{*}, \underline{t}_{\alpha \delta}^{*}\right)$, to distinguish them from those (namely $\Gamma_{\alpha}$ ) offered by owners with risk aversion $\gamma<\delta$. Then it follows that $\bar{t}_{\alpha \delta}^{*}>\bar{t}_{\alpha}^{*}$ and $\underline{t}_{\alpha \delta}^{*}<\underline{t}_{\alpha}^{*}$. But then $E U\left(\Gamma_{\alpha} ; \alpha\right)>E U\left(\Gamma_{\alpha \delta} ; \alpha\right)$ for all risk averse $\alpha$ workers. Hence no $\alpha$ workers would work for $\delta$ owners: all would prefer to work for $\gamma$ owners. Effectively, $\delta$ owners ask their workers to bear an unacceptable amount of risk compared with what is available elsewhere. The only way that a $\delta$ individual could attract workers is to incorporate a risk premium into the contract; but this makes them a higher cost producer than a $\gamma$ type.

Hence for new entrants to compete they must have risk aversion $\delta \leq$ $\gamma$. Recall from assumption A2 earlier that $\gamma=\alpha<\beta$. Hence if new entrepreneurial firms are to exploit new available niches, we must have $\delta=$ $\alpha=\gamma$. In short, $\alpha$ types are lower cost producers in the new niche than $\beta$ types are, since $\alpha$ s do not have to pay their workers the risk premium that $\beta$ types do; hence the new entrepreneurs are $\alpha \mathrm{s}$, who have the same risk attitudes as incumbent small firm owners. These $\alpha$ types have already sorted themselves into small firms, as established earlier: hence small firms

\footnotetext{
${ }^{4}$ Thus competition may eliminate at an early stage inefficient rivals jockeying for domination of a new niche. It would obviously be possible to introduce greater structure into this part of the model in terms of (for example) heterogeneous worker abilities to identify and exploit opportunities in entrepreneurship; however, this would not change the essence of the results below.
} 
generate the entrepreneurs, as observed empirically by previous researchers (Boden, 1996; Wagner, 2004).

Finally, the foregoing logic can also be used to predict that if the number of niches (or entrepreneurial opportunities more generally) declines, the entrepreneurs who exit return to work as employees in small firms. So if the number of entrepreneurial opportunities then expanded again, these workers, with experience of business ownership - but more fundamentally, with low risk aversion - are more likely to re-enter business ownership than workers without this experience (which includes employees of large firms). Hence, without controlling for risk aversion, one would expect to observe a positive association between previous self-employment experience and the likelihood of entry into entrepreneurship - even in the absence of any productivityenhancing benefit from experience. As noted in the Introduction, numerous previous empirical studies have detected an association of this kind (for a more comprehensive survey, see Parker, 2004, Chap. 3).

\section{Concluding Discussion}

The model developed in this paper predicts that small firms will offer a more variable wage than large firms, and attract relatively less risk-averse individuals to work for them. In equilibrium there is negative assortative matching between business owners and their workers by risk attitude, and grouping of workers (and entrepreneurs) by similar risk attitude. ${ }^{5}$ Because of the nature of risk preferences embodied in risk-sharing contracts, our model also predicts that workers in small firms are more likely to become entrepreneurs than workers in large firms.

The transition from employee to entrepreneur in the model involved the exploitation of a limited number of niches. It is important to note that niches were just a convenient simplification; alternative mechanisms such as borrowing constraints would generate similar outcomes. For example, suppose agents differ in their wealth; have preferences that exhibit decreasing absolute risk aversion; and face borrowing constraints which enable rents to be extracted in the business ownership sector. Because wealthier in-

\footnotetext{
${ }^{5}$ Other researchers have also modelled grouping of entrepreneurs by type, including Ghatak (1999) in the context of joint liability credit contracts. The matching there is by ability; different applications have analysed conventional credit contracts which sort entrepreneurs into separate risk classes to reveal hidden borrower types (e.g., Bester, 1985).
} 
dividuals find it easier to overcome borrowing constraints, less risk-averse individuals are once again predicted to be found both working in small firms and engaging in entrepreneurship. Thus borrowing constraints can replace niches without changing the key results. The advantage of constructing a model with niches rather than borrowing constraints is that one can bypass secondary issues entailed with wealth and borrowing constraints, such as strategic saving and effort decisions, wealth distribution dynamics, and the possibility of separating equilibria emerging in the credit market as well (see, e.g., Ghatak et al, 2001, for an excellent treatment of these issues).

The mechanism explored in this paper differs in several important respects from the well-known model of entrepreneurial participation proposed by Kihlstrom and Laffont (1979). That model assumed that all entrepreneurs perfectly smooth workers' wages, so less risk-averse individuals become entrepreneurs in that model too. In contrast, perfect wage smoothing is not offered by small firm owners in our model, since they can do better by sharing some of the risks with their workers. It is only larger firms, in which risk can be diversified more easily, or in which owners are more or less risk neutral, that substantial wage smoothing is practised. It is noteworthy that the Kihlstrom and Laffont (1979) model did not consider moral hazard problems. It is well known that full insurance contracts can be inefficient when workers have incentives to shirk; extensions of Kihlstrom and Laffont's model to allow for this seems to generate implausible outcomes (see, e.g., Newman, 2003). In contrast, our model has partial insurance of some workers and so its key predictions are robust to moral hazard considerations.

The model's predictions also appear to fit several stylised facts. As well as being consistent with evidence that workers in small firms are more likely to become entrepreneurs than workers in large firms, the model also predicts a positive association between the likelihood of new firm formation and previous self-employment experience - as has been observed by previous researchers. At the same time, it predicts that less risk-averse individuals are more likely to become entrepreneurs, in accordance with other theoretical models (Kihlstrom and Laffont, 1979; Parker, 1996) and a growing body of evidence (van Praag et al, 2002; Ekelund et al, 2005; Puri and Robinson, 2005). Of course, it is possible that alternative explanations might also fit these facts. Such explanations include the possibility that workers in small firms more easily gain productive experience or enjoy close prox- 
imity to inspirational entrepreneurs, from whom they can learn how to be effective entrepreneurs themselves. Alternatively, small firms might play an important part in pioneering spin-off companies. One therefore hopes that future empirical research might distinguish between these competing explanations and subject the selection theory to empirical testing. This holds out the promise of extending further our understanding of the role played by incumbent firms in the entrepreneurial entry process. 


\section{References}

Bester, H. (1985) Screening vs. rationing in credit markets with imperfect information, American Economic Review, 75, pp. 850-55.

Boden, R. J. (1996) Gender and self-employment selection: an empirical assessment, Journal of Socioeconomics, 25, pp. 671-82.

Ekelund, J., Johansson, E., Jarvelin, M-J., and D. Lichtermann (2005) Selfemployment and risk aversion - Evidence from psychological test data, Labour Economics, 12, pp. 649-59.

European Commission (2003) Green Paper Entrepreneurship in Europe, Brussels: European Commission.

Evans, D. S. and L. S. Leighton (1989) Some empirical aspects of entrepreneurship, American Economic Review, 79, pp. 519-35.

Ghatak, M. (1999) Group lending, local information and peer selection, Journal of Development Economics, 60, pp. 27-50.

Ghatak, M., Morelli, M. and Sjostrom, T. (2001) Occupational choice and dynamic incentives, Review of Economic Studies, 68, pp. 781-810.

Gompers, P., Lerner, J. and D. Scharfstein (2005) Entrepreneurial spawning: Public corporations and the genesis of new ventures, 1986 to 1999, Journal of Finance, 60, pp. 577-614.

Kihlstrom, R. E. and J.-J. Laffont (1979) A general equilibrium entrepreneurial theory of firm formation based on risk aversion, Journal of Political Economy, 87, pp. 719-49.

Laffont, J.-J. and D. Martimort (2002) The Theory of Incentives: The Principal-Agent Model. Princeton, NJ: Princeton University Press.

Newman, A. (2003) Risk-bearing, entrepreneurship and the theory of moral hazard, Mimeo, http://www.stanford.edu/group/SITE/Newman.pdf

Parker, S. C. (1996) A time series model of self-employment under uncertainty, Economica, 63, pp. 459-75.

Parker, S. C. (2004) The Economics of Self-employment and Entrepreneurship. Cambridge: Cambridge University Press.

Praag, C. M. van and H. van Ophem (1995) Determinants of willingness and opportunity to start as an entrepreneur, Kyklos, 48, pp. 513-40.

Praag, C. M. van, J. S. Cramer and J. Hartog (2002) Low risk aversion encourages the choice for entrepreneurship: An empirical test of a truism, Journal of Economic Behavior \&3 Organization, 48, pp. 29-36. 
Puri, M. and D. T. Robinson (2005) Optimism, entrepreneurship and economic choice, Duke University Working Paper.

Wagner, J. (2004) Are young and small firms hothouses for nascent entrepreneurs? Working Paper No. 301, University of Luneburg. 